\title{
Lo bello y lo útil, el esteta y el etnógrafo: El caso del Museo Etnográfico de Trocadero y del Museo del Hombre (1928-1940)
}

por

Christine Laurière ${ }^{1}$

EHESS, IIAC-LAHIC, París

Abordar la cuestión de la relación entre lo bello y lo útil despierta un interés mayor en Francia desde hace una década y media, a raiz de la puesta en marcha del proyecto del museo del Quai Branly, que revivió ciertos debates sobre la pertinencia y el valor respectivos de las miradas etnográfica o estetizante sobre objetos provenientes de sociedades no occidentales. Este artículo quisiera darle un poco de profundidad histórica a este tema refiriéndose a lo ocurrido en el Museo de Etnografía de Trocadero y en el Museo del Hombre durante las direcciones de Paul Rivet y de Georges Henri Rivière en los 1930.

Palabras Clave: Museo antropológico; Museo del Trocadero; Museo del Hombre de Paris; Museo del Quai Branly; Paul Rivet; Georges Henri Rivière; arte; etnografía.

\section{LA INSTRUMENTALIZACIÓN DE UN VIEJO DEBATE}

Abordar la cuestión de la relación —amistosa u hostil— entre lo bello y lo útil despierta un interés mayor en Francia desde hace una década y media, a raíz de la puesta en marcha del proyecto del museo del Quai Branly, que revivió - y digo claramente «revivió», no que «creó»— ciertos debates sobre la pertinencia y el valor respectivos de las miradas etnográfica o estetizante sobre objetos provenientes de sociedades no occidentales. Quisiera darle un poco de profundidad histórica a este tema refiriéndome a lo ocurrido en el $\mathrm{Mu}$ -

1 Este trabajo se inscribe en el proyecto de investigación «Museos, memoria y antropología: América y otros espacios de colonización», financiado por el Ministerio de Ciencia e Innovación del Gobierno de España (referencia: HAR2009-10107). Traducción de Guillermo Vargas Quisoboni. 
seo de Etnografía de Trocadero y en el Museo del Hombre durante las direcciones de Paul Rivet (1876-1958) y de Georges Henri Rivière (1897-1985). Con esto no pretendo atenuar la singularidad del Museo del Quai Branly², sino más bien reiterar ciertas semejanzas, incluso mostrar la recurrencia, el aspecto cíclico de ciertas maneras de decir y de hacer comunes al Museo de Etnografía de Trocadero (MET), al Museo del Hombre (MH) y al Museo del Quai Branly (MQB), cada uno de los cuales se proclamó como punta de lanza de la modernidad en su época propia. Si observamos el discurso vehiculado por el MQB, resulta evidente que en él se quiso hacer tabula rasa del pasado creando una disociación muy fuerte, casi podría decirse violenta, frente al MH. Pienso particularmente en ciertas expresiones virulentas de Jacques Kerchache ${ }^{3}$ como cuando afirmaba que el arte no requería apoyarse en «las muletas inútiles de la etnografía», y en las dificultades que han tenido los etnólogos para hacer valer su punto de vista en este proyecto. Con todo, si observamos lo ocurrido en la práctica, las cosas toman un aspecto distinto. No puedo evitar proponer una serie de comparaciones que algunos podrían juzgar de anodinas o insignificantes y que otros habrían podido considerar previamente. Pero, vistas en su conjunto, esas comparaciones nos permitirán cuando menos sensibilizarnos a la historia de los museos etnográficos parisinos, y desprender de ello lo que se podría definir como «los lugares comunes» de los museos etnográficos.

En primer lugar, resulta inevitable constatar que, cada 60 años, un nuevo museo etnográfico ha sido creado en París. El año de 1878 vio el nacimiento del Museo de Etnografía de Trocadero, 1938 el del Museo del Hombre, y en 1996 fue el lanzamiento del proyecto del Museo del Quai Branly. Es como si existiera la necesidad de redefinir periódicamente al Otro y el lugar que ocupa dentro de nuestra sociedad en función de nuevos cánones, dentro de un contexto político, económico y social diferente. En cierta medida, es también

2 Existe una bibliografía abundante sobre el museo del Quai Branly. Algunas referencias que ponen en perspectiva crítica al museo son Ventura, 2006. De L'Etoile, 2007. Price, 2007. Dias, 2008.

3 Comerciante de arte y coleccionista francés, Jacques Kerchache (1942-2001) es el autor del manifiesto «Para que las obras maestras del mundo entero nazcan Libres e Iguales» publicado en el periódico Libération el 15 de marzo de 1990, y firmado por personalidades científicas y culturales incluyendo varios antropólogos. Este manifiesto se inscribe históricamente en prolongación de un deseo expresado en 1920 por el crítico de arte Félix Fénéon, quien publicó una encuesta en forma de alegato en torno a la pregunta «¿Irán hacia el Louvre? Estudio sobre las artes lejanas» (Fénéon, 1920). El encuentro entre Jacques Kerchache y Jacques Chirac en el verano de 1991 fue decisivo pues condujo a la creación del Pabellón de las Sesiones del museo del Louvre en el año 2000 y a la fundación del museo del Quai Branly. 
nuestro propio lugar el que redefinimos en cada ocasión. Si se piensa en la regularidad del ciclo de sesenta años que transcurre entre cada nueva organización museística, es probable que dentro de cincuenta años, o menos, haya una redefinición profunda, radical, de las misiones actuales del Museo del Quai Branly. Este tipo de museo tiene una obsolescencia bastante rápida, que no resulta tan sorprendente en tanto refleja el vínculo de la nación con un lugar donde se conceptualiza su relación forzosamente problemática y evolutiva con el mundo, la alteridad, que refleja también la visión que la nación francesa tiene de su papel y su destino propios dentro del mundo. La duración de esos museos etnográficos no es comparable con la de los museos de bellas artes, que no sufren de una reevaluación tan profunda de sus bases. En este sentido, resulta particularmente relevante evocar la noción de modernidad, pues, en su definición misma, la modernidad es algo que caduca rápidamente. No cabe duda de que, después de una década de ser moderno, de ser una atracción, el modelo del Museo del Hombre se estancó por la falta de un apoyo político e institucional fuerte. Por ejemplo, el presupuesto financiero del museo se redujo al dinero recaudado con los tiquetes de entrada. También hizo falta un sucesor de peso que reemplazara a Rivet después de su jubilación, alguien con una visión clara de las nuevas misiones de la institución en un mundo en total transformación geopolítica, frente al movimiento producido por la descolonización y la guerra fría y con capacidad de adaptarse a un entorno científico totalmente diferente, puesto que la antropología estaba cambiando de paradigma, pasando de una etnografía de salvamento hacia una antropología social y simbólica que no requería más de ningún objeto como soporte, que no necesitaba más de un museo etnográfico para definir su identidad y fortalecer su legitimidad.

En segundo lugar, la metáfora del viaje, de la evasión hacia países exóticos ha sido un leitmotiv en los anuncios publicitarios destinados al gran público. El Museo del Hombre había escogido como gancho para atraer turistas extranjeros la frase: «When in Paris See the World in two hours». Entretanto, el Museo del Quai Branly proponía «dar la vuelta al mundo en 60 minutos». Al parecer, en un mundo más estrecho y más rápido, iya nos hemos ahorrado una hora!

En tercer lugar, cuatro años después de que Rivet y Rivière tomaran las riendas del Museo de Etnografía de Trocadero, en 1932, este marcó su gran retorno a la escena etnográfica y artística parisina con una exposición memorable sobre Benin, la primera de tal envergadura en este país, que fue organizada por Charles Ratton, galerista y coleccionista de arte primitivo. Esta exposición obtuvo un gran éxito frente al público y los amateurs. Poco después de su inauguración, en 2007, en el Museo del Quai Branly se realiza una exposición 
sobre «Benin, cinco siglos de arte real», en la cual pueden verse varias piezas que habían sido expuestas en Trocadero en ese entonces.

En cuarto lugar, el MQB tiene actualmente una sucursal, una embajada en el Louvre, el Pabellón de las Sesiones, que contiene un centenar de obras maestras totalmente desarticuladas de un discurso etnográfico. En su momento, el MET tuvo un equivalente en su «sala del tesoro»; a partir de 1932, los objetos que esta sala albergaba eran seleccionados por su calidad plástica y por el placer que procuraban a la mirada del esteta. Por lo demás, los objetos expuestos en el Pabellón de las Sesiones provienen casi todos de la selección realizada para la gran exposición de 1965 en el MH, que reunía las obras maestras de la colección, así como los objetos de la célebre exposición «Artes primitivas en talleres de artistas en 1967». Según mi conocimiento, el MQB es el único museo en el mundo cuyas más bellas piezas, las más destacadas, son mostradas en las salas de otro establecimiento museístico, y no en las suyas propias. Esto muestra bien la fuerza de ese viejo sueño de ver a las artes primitivas en el Louvre, museo universal por excelencia, sueño que fue nuevamente realizado por Jacques Kerchache en los años 1990.

En quinto lugar, ya el MH había mostrado un deslizamiento de interés pasando de exponer la cultura de los otros a exposiciones sobre la historia de la etnografía y de las colectas hechas durante el trabajo de campo por los etnólogos, a través de exposiciones, permanentes y temporales, como la de «Las Américas de Claude Lévi-Strauss» (1992), la del «África de Marcel Griaule» $(1998 / 1999)$ y la del viaje del velero La Korrigane por los mares del Pacífico Sur (2001). Como una suerte de ironía de la historia, podemos notar que esta exposición sobre La Korrigane fue al mismo tiempo la exposición inaugural del MH en 1938 y su última exposición en 2003. El MQB ha prolongado la tradición de hacer exposiciones dedicadas a coleccionistas y etnógrafos. Su primera exposición itinerante en el Museo de Artes de África y Oceanía (MAAO), en 2002, fue dedicada a «Kodiak, Alaska, las máscaras de la colección Alfonso Pinart». Para hacer memoria, debe recordarse aquí que la primera exposición del MH también fue itinerante, pues tuvo lugar en la galería Wildenstein, con una selección de objetos de los indígenas del Matto Grosso brasileño que fueron traídos por Claude y Dina Lévi-Strauss. Y en 2007/2008, tuvo lugar en el MQB la exposición «El aristócrata y sus caníbales», a propósito del viaje del Conde Rodolfo Festetics de Tolna en Oceanía en aras de «resucita(r) la magia del Pacífico de finales del siglo XIX».

Finalmente, el último paralelo que deseo destacar es el de un cierto parentesco en la filosofía evocada para justificar la creación de ambos museos. Los dos han pretendido reparar una injusticia histórica y social para otorgarle el lugar que le corresponde a sociedades y civilizaciones injustamente desconoci- 
das, desconsideradas, despreciadas y rechazadas. La diferencia entre ellos radica en la manera en que se ha decidido llevar a cabo dicha reparación: el MQB ha escogido deliberadamente una rehabilitación a través del arte, que sería la más prestigiosa, mientras que el $\mathrm{MH}$ resultó ser menos selectivo y más ambicioso, pues pretendió agarrar varios toros con una sola mano, es decir, reevaluar simultáneamente los aspectos etnográfico, estético y técnico. En efecto, una de las grandes revoluciones en la museografía del MH fue esa famosa sala de las Artes y las Técnicas en la que se valorizaba el aspecto formal y plástico de los objetos, del saber-hacer y de todos los aspectos cognitivos requeridos para su realización ${ }^{4}$. Retomaré este punto más adelante, pues merece un mayor desarrollo.

Estas consideraciones preliminares tienen como único propósito sensibilizar al lector sobre la existencia y el sentido de ciertas recurrencias. La oposición entre discurso etnográfico y discurso estético, que ha sido frecuentemente instrumentalizada, es un coro que ha sido varias veces cantado. Ya entre los años 1920 y 1930, la idea de que el museo de etnografía corría el riesgo de ser reemplazado por un museo de bellas artes se volvió recurrente, especialmente a partir de 1928, cuando el Museo de Trocadero fue salvado del estado de abandono en que se encontraba. Este es el caso sobre el cual voy a profundizar ahora.

LA EXPOSICIÓN «LAS ARTeS ANTIGUAS DE AmÉRICA» (1928):

LA RESURRECCIÓN PARADÓJICA DE TROCADERO

El 6 de marzo de 1928, Paul Rivet fue nombrado profesor titular de la cátedra de antropología del Museum de historia natural ${ }^{5}$. Un decreto del 27 de marzo de 1928 ordenaba que la dirección del Museo de Etnografía de Trocadero fuera anexada al profesor titular de esta cátedra. De hecho, desde la creación del Museum en 1878 se había vuelto tradición que el profesor de antropología asumiera el cargo de conservador en jefe de Trocadero. El primero en hacerlo fue Hamy, hasta 1907, y después René Verneau hasta 19286. Esta afiliación entre las dos instituciones era una condición sine qua non para que Paul Rivet aceptara dirigir el Trocadero sin un salario suplementario. La inten-

4 Grognet, 2008: 424-426, 482-485.

5 Sobre Paul Rivet, véase Laurière, 2008.

6 Sobre la creación del Museo de Trocadero, véase Dias, 1991. Hamy, 1988. Laurière, 2008: 372-374. 
ción de dicho decreto era combatir el aislamiento institucional del museo, articularlo a un gran establecimiento científico que le permitiera afianzar su identidad. El museo se encontraba en un estado lamentable y poseía un presupuesto insignificante. La tarea de levantarlo y reorganizarlo iba a ser dura. Por esto Paul Rivet se dedicó a buscar un subdirector competente que pudiera asistirlo eficazmente y que fuera capaz de ejecutar las acciones previstas. La elección de Georges-Henri Rivière (1897-1985) fue resultado de una serie de coincidencias determinantes en las cuales se expresaba ya la relación problemática, compleja, entre etnografía y bellas artes. Era difícil imaginar dos personalidades tan disímiles como las de Rivet y Rivière, pero el dúo funcionó bien contra todo pronóstico. Lograron alcanzar resultados que iban más allá de las metas que fijaron al principio de su asociación, puesto que consiguieron unir estrechamente los destinos de la etnología y de Trocadero en una época en que, tanto en Europa como en Estados Unidos, la etnología se emancipaba de los museos etnográficos para darle prioridad a sus vínculos con la universidad y con el mundo de la investigación científica.

Vale aclarar que Georges-Henri Rivière no poseía una formación académi$\mathrm{ca}^{7}$ : era un músico aficionado, un dandy que pasaba las noches en fiestas y que frecuentaba a los artistas de las vanguardias. Había estudiado en la Escuela del Louvre, trabajado en una galería de arte y desde 1926 se había convertido en intendente de las colecciones de arte del financiero y mecenas David David-Weill $^{8}$. Rivière reivindicaba su diletantismo, declaraba abiertamente ser un adepto del modernismo y tenía un gusto artístico bien consolidado. De manera episódica participaba en la revista de vanguardia los Cahiers d'art escribiendo artículos cortos. Después de la boga del arte negro, las artes oceánicas y precolombinas se convirtieron en las favoritas de los artistas, especialmente de los surrealistas. Cuando el director de los Cahiers d'art quiso aprovechar el interés que había generado la exposición «Yves Tanguy y los objetos de América», presentada a comienzos de 1927 en la galería Surrealista, buscó a Georges-Henri Rivière para encargarle la redacción de un artículo sobre arte precolombino. Rivière fue enviado a tantear terreno en Trocadero, donde podría extraer la materia necesaria para evocar este arte. Pero, al terminar su visita, Rivière se sentía «cautivo» $\rangle^{9}$. Había quedado convencido de que el arte preco-

7 Sobre Rivière, véase Leiris, 96 (París, 1985): 37-140. Leroux-Dhuys, 1989. Chiva, 5 (París, 1984): 76-83. Gorgus, 2003.

${ }^{8}$ Conf. los Titres et travaux de Rivière Georges-Henri, Archives de la Biblioteca central del Museum nacional de historia natural (BCM), París, Estado, carpeta Rivière, 2 AM 1 K83b.

9 Rivière, «Musée de l'homme à travers mes temps», entrevista inédita citada en Leroux-Dhuys, 1989: 22-23. 
lombino merecía mucho más que diez líneas escritas en un artículo, y fue entonces cuando decidió organizar una exposición ${ }^{10}$.

Para albergar la futura exposición, Rivière escogió el pabellón Marsan del museo de Artes Decorativas. Tal decisión estaba muy lejos de ser anodina, puesto que se trataba del mismo lugar donde había sido realizada, a finales de 1923, la célebre exposición de arte indígena de las colonias francesas, cuyo éxito había sido considerable. En ese mismo pabellón, el público francés también había comenzado a familiarizarse con el arte musulmán, el arte japonés y el arte khmer. Rivière deseaba marcar un hito mostrando por primera vez en Francia el arte de esta región del mundo. Así pues, con el apoyo económico de David-Weill, Rivière conformó un pequeño equipo de trabajo para preparar la exposición: Georges Bataille le había presentado a Alfred Métraux, un antiguo compañero suyo de la Escuela de Chartes. Rivière y Métraux, que eran dos jóvenes de la misma generación, se entendieron muy bien. Métraux, que era americanista y cuya tesis doctoral versaba sobre los Tupí Guaraní, sería el garante etnológico de la exposición. También formaban parte del equipo André Schaeffner, musicólogo y autor de uno de los primeros libros sobre jazz publicados en Francia; Georges Salles, conservador adjunto del Louvre para el departamento de Extremo Oriente; y por último Ernst Gutzwiller y Alexandre Bungener, aficionados y coleccionistas de arte.

Dado que se trataba de la primera vez que el arte precolombino era objeto de una manifestación de tal envergadura, todos coincidían en que había que darle prioridad a mostrar los aspectos formales y plásticos de las obras seleccionadas, y no dedicarle mucho tiempo al punto de vista etnográfico que los expertos desarrollaban basándose en el estudio detallado de las piezas. Implícitamente, lo que se buscaba era que estas obras pudieran salir de los «laberintos subterráneos de Trocadero» ${ }^{11}$ en donde vegetaban. Luego, cuando el interés del público hubiera sido estimulado, se podía pensar en otro tipo de conocimiento de las obras alimentado por el trabajo fecundo de los expertos, que se despojaría así de un cierto hermetismo. Georges Salles, uno de los artífices de la exposición, insistía en evitar la formulación de una oposición estéril —además de vulgar - entre arte y ciencia:

El objetivo de esta exposición [...] es extraer de un terreno puramente científico ciertos objetos [...] que también merecen ser considerados desde un punto de vista artístico. Con esto, la ciencia no tiene nada que perder. Por el contrario, la fuerza de atracción que ejerce el arte despertará la curiosidad del público por las antiguas ci-

10 Sobre esa exposición decisiva, véase Laurière, 33 (París, 2003): 57-66. Laurière, 2008: 374-384.

11 Poncetton, 39 (París, 1928): 65. 
vilizaciones americanas y motivará numerosas investigaciones. [...] El público al convertirse en amateur exigirá que los objetos sean estudiados de manera cada vez más minuciosa. Los comerciantes de arte y los coleccionistas se convertirán en los ayudantes y los auxiliares de los investigadores ${ }^{12}$.

El sábado 12 de mayo de 1928, en el mejor momento de la temporada cultural parisina, la exposición «Las artes antiguas de América» («Les Arts anciens de l'Amérique») abría sus puertas en cuatro salas del pabellón Marsan. En el recorrido, que incluía objetos provenientes de todo lo largo de la América precolombina, desde el estrecho de Behring hasta el cabo de Hornos, el público podía observar una gran variedad de piezas: columnas totémicas, máscaras, vestidos de plumas, cerámicas. La clasificación de los objetos había sido establecida por cada país y luego en función de la materia prima empleada. La exposición era sorprendente, deslumbrante, y alcanzó un verdadero éxito entre los artistas, los aficionados, y la comunidad científica. Las reseñas eran ditirámbicas. Tras un mes y medio, la exposición había atraído a cerca de diez mil visitantes. A decir verdad, el éxito alcanzado por la exposición consistía en haber inspirado un amor a primera vista por un arte desconocido en Francia. Fue una exposición que marcó un hito más allá del Hexágono. Su influencia fue tan fuerte que, cuatro meses más tarde, la Academia de Bellas Artes de Berlín, siguiendo el ejemplo de lo ocurrido en París, presentó también una exposición de arte precolombino ${ }^{13}$.

El éxito de este evento que había sido iniciado y propiciado por Georges-Henri Rivière también constituía paradójicamente un éxito para el Museo de Etnografía de Trocadero, en la medida en que el gran público y la comunidad científica y artística en verdad estaban descubriendo, en condiciones apropiadas - iy sobre todo en las salas de exposición de otro museo parisino! - la riqueza excepcional de la colección del MET. Esto había quedado muy claro para todo el mundo, hasta el punto de que el americanista y coleccionista Raoul d'Harcourt, en la introducción al catálogo de la exposición, no pudo evitar expresar su deseo de que las condiciones inesperadas que habían beneficiado a la exposición pudieran beneficiar en fin de cuentas a «nuestro museo de Trocadero» ${ }^{14}$. El público «comprenderá más precisamente el interés profundo de las colecciones conservadas en las ricas galerías del museo de Trocadero que solo requieren, para poder salir de las tinieblas y del polvoriento letargo en el que se encuentran, de una presentación nueva, un reagrupamiento minucioso y una mayor iluminación. Por muy grande que parezca esta labor, ahora es-

\footnotetext{
12 Guardia, 39 (París, 1928): 82.

13 Lehmann, 1965: 154.

14 D'Harcourt, 1928: XI.
} 
tamos convencidos de que será realizada gracias a la dinámica de la nueva dirección» ${ }^{15}$. Al contrario de la opinión proferida por Elizabeth Williams ${ }^{16}$, Raoul d'Harcourt no expresaba ningún tipo de «malestar» ni «dudas» respecto del tratamiento deliberadamente artístico aplicado sobre objetos revestidos de un carácter ritual o utilitario evidente. En lugar de ello se mostraba totalmente de acuerdo y lo justificaba argumentando que «la estética en una acepción amplia pertenece a esta ciencia (la etnografía) dentro de la cual ocupa incluso un lugar privilegiado», puesto que «la idea de belleza que se añade y se incorpora» a estos objetos hace parte integral de su estudio. Pero también reconocía que un museo de etnografía, cuya «misión es mucho más general», estaba obligado a «subordinar el aspecto estético para responder a otras exigencias»; y era precisamente ahí donde radicaba «el interés de la exposición del Museo de Artes Decorativas» que lograba liberarse de tales imperativos ${ }^{17}$. Por su parte, Georges Salles se mostraba convencido de que «el Museo de Etnografía de Trocadero no deb(ía) arrepentirse de su propuesta generosa. El público (tenía) la oportunidad de determinar cuántas obras de gran valor (había) en su interior. $\mathrm{Si}$ las colecciones de Trocadero fueran presentadas en un marco que estuviera a la altura, como el del Museum für Völkerkunde de Berlín, se formaría incontestablemente uno de los más bellos museos de etnografía de Europa» ${ }^{18}$. Paul Rivet compartía esta opinión. La exposición del museo de Artes Decorativas se había convertido en una caja de resonancia maravillosa para mostrar el brillo de una colección que todavía esperaba ser descubierta por el público. Había que aprovechar la coyuntura para sentar las bases de una renovación radical del museo de Trocadero que le permitiera a la vez popularizar la civilización material de las sociedades exóticas y vulgarizar los avances de la etnología.

Paul Rivet, quien había sido invitado a la inauguración, tenía más de un motivo para apreciar la exposición. Además de ser americanista y un auténtico conocedor de la orfebrería y la cerámica suramericanas, había prestado algunas piezas de su colección personal para la exposición. Pero lo más importante es que se trataba del recién nombrado director del museo de etnografía de Trocadero, y ya para entonces sabía que debía encontrar muy rápidamente a un subdirector enérgico e innovador para poder convertir este sitio cultural en un lugar reconocido y popular. Sabemos que había «admirado la exposición» ${ }^{19} \mathrm{y}$ que había quedado favorablemente impresionado por el talento del organiza-

\footnotetext{
15 Idem.

16 Williams, 1985: 146-147.

17 D'Harcourt, 1928: XI.

18 Guardia, 39 (París, 1928): 83.

19 Rivière en Leroux-Dhuys, 1989: 23.
} 
dor Georges-Henri Rivière quien había sabido producir un evento y atraer a todo París para descubrir un «arte oscuro». A través de amigos comunes, Rivet le puso a Rivière una cita en su oficina del Museum. Este suceso pasó a la posteridad en la historia de la etnología francesa como uno de los momentos fundadores de la etnología moderna, causó profundas repercusiones en su organización y en su devenir. El profesor Rivet quiso saber dónde había realizado su tesis Rivière, cuáles eran sus títulos universitarios. Aunque confundido por la pregunta, este último le explicó que solamente era bachiller, pero que había tomado clases en la Escuela del Louvre. Después de un silencio, Paul Rivet consideró que eso no significaba nada y fue así como terminó ofreciéndole el puesto de subdirector, pidiéndole su colaboración para la renovación de Trocadero. Paul Rivet le dijo: «yo me encargo de hacer ciencia, usted se encarga de hacer todo lo que implica elaborar una traducción popular de esta ciencia. Soy un hombre de pueblo, y quiero fundar un gran museo de cultura popular» ${ }^{20}$.

Sin duda alguna, el profesor demostraba su audacia al asociarse para la reorganización del museo con un joven de tan solo treinta años que no estaba cualificado científicamente. Tenía apenas un diploma y jamás había publicado un artículo que hubiera contribuido en algo al avance de la reflexión etnológica. Hoy en día sería impensable e imposible otorgar a una persona con ese perfil y de esa edad un puesto de tan alta responsabilidad, la subdirección de un museo de etnografía. Tan pronto llegase a la oficina del director, el curriculum vitae de dicho candidato iría a la basura. Pero Paul Rivet no era un hombre que se detenía fácilmente en ese tipo de consideraciones conformistas. Después de haber visto en acción a Georges-Henri Rivière durante la exposición «Las artes antiguas de América», se había dado cuenta de lo que era capaz. Rivière poseía cualidades que valían más que cualquier diploma universitario. Era entusiasta, enérgico, perseverante, tenía una férrea voluntad para lograr sus propósitos y vencer los obstáculos. A posteriori, Georges-Henri Rivière se mostraría como el hombre adecuado: era joven y poseía un don de gentes poco común, tenía un directorio de contactos muy completo, exhibía un gusto y un sentido museográficos bien definidos, conocía a la gente del mundo artístico y de las vanguardias. Lo único que faltaba era que su enorme capacidad de organización fuera bien canalizada. Una feliz coincidencia permitió que entraran al museo casi al mismo tiempo, con unos pocos meses de diferencia. Y es por eso que el reposicionamiento del museo fue indudablemente el resultado de un trabajo conjunto. Rivière se había ganado el derecho a participar en dicha empresa y lo hizo con un compromiso inequívoco. El dúo conformado por Rivet y Rivière en la dirección del museo

20 Breerette y Edelmann, 1979: 16. 
marcó el inicio de un periodo feliz de diez años que constituyó la «gran aventura» de Trocadero, según decía el propio Rivière ${ }^{21}$, y que concluyó con el lanzamiento de un proyecto museístico inédito (el Museo del Hombre) en torno a un concepto original: el museo-laboratorio.

\section{¿Museo de Bellas Artes o museo de etnografía?}

La experiencia que acreditaba Rivière y las coincidencias que condujeron a su nombramiento en la subdirección del museo alimentaron la incertidumbre del destino que le deparaba a Trocadero, entre museo de etnografía y museo de Bellas-Artes. En su momento, Rivière era más conocido por su gusto artístico que por sus diplomas. Por eso, en un principio, Marcel Mauss no ocultaba sus reservas frente a este. A comienzos de 1929, le reprochaba que hubiera hecho una presentación artística de las salas, aunque simplemente hubiera limpiado el espacio, realizado una nueva selección de las piezas y las hubiera dispuesto mejor ${ }^{22}$. Una cierta confusión había sido creada durante la exposición del pabellón Marsan y bajo la cual las fronteras entre bellas artes y etnografía parecían diluirse. Para hacerle frente, Rivière redibujaba vigorosamente los límites sobre el tablero, con una vehemencia que se justificaba por el conocimiento preciso que tenía de sus adversarios y de lo que estaba realmente en juego en Trocadero ${ }^{23}$.

En París, el Museo Etnográfico de Trocadero distaba mucho de ser el único lugar donde podían contemplarse obras exóticas. Además de ciertos museos (como el museo Guimet, el de la marina, el de Sèvres, el de Saint-Germain-enLaye), había numerosos coleccionistas y varios comerciantes de arte que montaban exposiciones en galerías de arte, quienes habían presentado, bajo un ángulo puramente estético, una serie de piezas africanas desde comienzos de los años 1900 y, más tarde, a partir de los años 20, piezas oceánicas y precolombinas. Tan solo en París podían contarse aproximadamente 150 colecciones particulares de arte primitivo ${ }^{24}$. Desde comienzos de siglo, el arte negro se había puesto frenéticamente de moda entre artistas e intelectuales. Este arte que se prestaba para encarnar todo tipo de fantasmas e inspirar toda clase de fantasías también representaba una alternativa estilística a los cánones clásicos y materializaba la multiplicidad de relaciones que otras sociedades humanas establecían con el mundo. La valorización de estas artes indistintamente llamadas «exóticas», «negras», «primitivas» o «salvajes» era más que un capricho pasajero, pues termi-

21 Rivière, 1968:187.

22 Laurière, 2008: 400-401.

23 Laurière, 2003.

24 Paudrat (Arquennes, 1996). 
naron insertándose durablemente en el paisaje cultural e intelectual de las elites parisinas. La boga del exotismo había alcanzado su apogeo a mediados de los años 20, gracias a espectáculos que habían hecho tambalear a las vanguardias, como los de Joséphine Baker y Florence Mills en el teatro de los Campos Elíseos en 1925 y 1927, el de Blackbirds presentando Porgy and Bess en el Moulin Rouge, o la proyección de la película Hallelujah, entre otros. En la misma época también aparecieron publicaciones especializadas, libros voluminosos dedicados a las artes oceánicas, africanas y americanas ${ }^{25}$.

Así pues, el museo de etnografía no aspiraba siquiera a detentar el monopolio del discurso legítimo sobre tales producciones indígenas, pues estaba rodeado de una multitud de iniciativas privadas cuyos objetos y temáticas eran igualmente las artes primitivas. Estas se habían convertido en el objeto de una lucha simbólica tan intensa que los parámetros de interpretación que le eran aplicados podían ser totalmente divergentes según fueran empleados por un artista, un comerciante, un coleccionista o un etnógrafo.

Paradójicamente, aunque la boga del arte negro beneficiaba indudablemente el interés creciente por el Museo de Etnografía de Trocadero y el aprecio por la etnología, Paul Rivet y Georges-Henri Rivière pretendían apartarse del campo artístico para darle resonancia a otro discurso. Paul Rivet era plenamente conciente de que «en el transcurso de los últimos años, gracias a la moda del exotismo, felizmente se había producido un fortalecimiento ${ }^{26}$ que beneficiaba a Trocadero. Sin embargo no consideraba que hubiera que contentarse con ello ni menos sembrar la confusión. Su propósito consistía en evitar que se impusiera un punto de vista estético que no hiciera justicia al valor de uso de las obras ${ }^{27}$, y las «amputara arbitrariamente de todo lo que pudiera reflejar su carácter jurídico, religioso, mágico e incluso su humilde pero sagrado valor utilitario» ${ }^{28}$. La posición asumida por Georges-Henri Rivière en la primera entrega de la revista $D o$ cumentos, en abril de 1929, en su artículo «El Museo de Etnografía de Trocadero», tenía el valor de un manifiesto sobre la manera en que el museo manejaría en el futuro estas divergencias sobre las cuotas de competencias disciplinarias y el estilo de presentación de los objetos reconocidos por su valor etnográfico ${ }^{29}$. Por lo demás, todo el equipo de redacción de la efímera revista Documentos compartía una cierta irritación contra el desvío del significado de las obras, con-

25 Paudrat, 1987.

26 Paul Rivet, Organisation des études ethnologiques, 14 de abril de 1931, p. 1, BCM, París, Estado, carpeta «Musée d'Ethnographie: notes et rapports (1930-1931)», 2 AM 1 G2d.

27 Según la palabra de Denis Hollier, 1991.

28 Rivière (París, 1931): 278.

29 Rivière, 1 (París, 1929): 54-58. 
tra la valorización exclusivamente estética del arte negro, que terminaba empobreciendo su recepción, en nombre de un egocentrismo formalista. Michel Leiris evocaba esta época en los mismos términos:

No queríamos saber nada más sobre «arte negro», que se había puesto tan de moda. La etnografía no podía verse reducida a lo que se denominaba «arte negro» ni al estudio de las artes exóticas. [...] Era un estado de ánimo que se había vuelto normal porque era una reacción contra la tendencia terriblemente estética que orientaba la mirada sobre dichas civilizaciones ${ }^{30}$.

A comienzos del año 1930, tuvieron lugar en París dos exposiciones privadas importantes, las últimas de tales dimensiones antes de que la coyuntura provocada por los efectos de la crisis de 1929 se volviera a sentir en Europa. La primera fue la «Exposición de arte africano y arte oceánico» organizada bajo la iniciativa de Philippe de Rothschild en la Galería del Teatro Pigalle, con cerca de 400 piezas dispuestas en una escenografía «deliberadamente estética $\rangle^{31}$. Las colecciones del museo de Trocadero no fueron muy solicitadas, mientras que las colecciones particulares fueron puestas en palco de honor. La segunda exposición, realizada en la Galería del Renacimiento, reunía más de 300 objetos en una presentación igual a la anterior. Georges-Henri Rivière expresaba de manera áspera la molestia que le causaba ver «esas empresas fúnebres de laicización $\rangle^{32}$ que, obnubiladas por los criterios de lo bello, transformaban las esculturas exóticas en obras maestras, sin pensar en su carga simbólica, en su aspecto práctico o en su eficacia social. Esta estetización desaforada neutralizaba y debilitaba el carácter potencialmente subversivo de obras que podían mostrar otras facetas de la condición humana, los caminos alternativos de la civilización. «Nosotros, en las futuras salas de Trocadero, mostraremos esos objetos con la mayor documentación posible», apuntaba Rivière:

Junto a un jarrón pondremos una explicación de su construcción, los procedimientos empleados y el significado de su decoración. Junto a una máscara pondremos el dibujo que un cronista hizo de ella dos siglos atrás, y en una reseña podrá saberse con qué sociedad secreta debe ser asociada. Un instrumento musical será visto en funcionamiento a través de una fotografía, una partitura musical mostrará su alcance, un disco permitirá escuchar su sonido ${ }^{33}$.

Contra todas las expectativas, esta voluntad de distanciarse de una postura estética parecía ser bien recibida por los comerciantes de arte que tenían mucho que ganar con un enriquecimiento del discurso sobre esos objetos y la le-

30 Price y Jamin, 4 (París, 1988): 40.

31 Paudrat (Arquennes, 1996): 50.

32 Rivière (París, 1931): 278-282.

33 Rivière (París, agosto-septiembre de 1931): 81-83. 
gitimidad que podían conferirles el museo y la universidad. De hecho, uno de los galeristas y coleccionistas parisinos más reputados e influyentes de la época, Paul Guillaume, no solo mantenía vínculos extremadamente cordiales con Georges-Henri Rivière y Paul Rivet, sino que además se había convertido en un apoyo activo a su empresa de renovación del museo. Fue a través suyo que Georges-Henri Rivière conoció a Albert Sarraut, quien era para entonces diputado, y quien ayudaría a conseguir los créditos necesarios para la renovación de Trocadero. Paul Rivet y Georges-Henri Rivière sentían un profundo reconocimiento hacia Paul Guillaume por su «defensa de Trocadero» y por su «ingeniosa demagogia del miedo» ${ }^{34}$ que contribuía eficazmente a sus propósitos. Paul Guillaume incitaba a varios de sus amigos a volverse miembros de la Sociedad de los Amigos del Museo de Etnografía de Trocadero. Tras su muerte prematura, Paul Rivet y Georges-Henri Rivière fueron parte de los primeros miembros de la nueva Sociedad de Amigos de Paul Guillaume, junto con Georges Braque, André Derain, Max Jacob, Henri Matisse y Picasso.

La crisis económica y la llegada al mercado del arte de una nueva generación de galeristas deseosa de cooperar con la valorización estética e ideológica de las sociedades productoras de esos objetos - entre quienes se encontraba Charles Ratton - llevaron al MET a recuperar su fuerza y a cambiar su situación entre los años 1932 y 1933. Su éxito de público podía demostrarlo. Conduciendo una ambiciosa propuesta de reacondicionamiento de las salas del museo en la que se enfatizaba su vocación pedagógica y científica y una activa política de exposiciones temporales que no ocultaba sus pretensiones estéticas, Paul Rivet y Georges-Henri Rivière ocuparon todo el terreno y lograron desempeñarse en los dos registros, el de museo científico en modo mayor, y el de museo de bellas artes en modo menor. Ya había pasado el momento de defender la especificidad científica del museo y había llegado el momento de la cooperación. Tres años después del comienzo de sus actividades, Georges-Henri Rivière había terminado reevaluando sus sentimientos, pues ya el museo había conseguido imponerse y hacerse valer en su propio campo:

Durante mucho tiempo fui injusto con ese fervor (del arte negro), que hoy me parece ser menos molesto, más sensible e incluso más legítimo. Aunque el origen de muchos objetos ha sido confundido, aunque muchos trabajos científicos de calidad han sido ignorados, debemos aceptar que los culpables de esta situación son los mismos que hicieron posible una de las más grandes épocas del arte de Picasso ${ }^{35}$.

34 Carta de Georges Henri Rivière y Paul Rivet a Paul Guillaume, 7 de marzo de 1934, BCM, París, Estado, carpeta Paul Guilaume, 2 AM 1 K46a.

35 Georges Henri Rivière, Prefacio al catalogo de la venta de Miré, 10 de diciembre de 1931, p. 2 del manuscrito, BCM, París, Estado, carpeta Ratton, 2 AM 1 K81b. 
La relación entre lo bello y lo útil suscita menos problemas que antes, pues cada uno ocupa un lugar claramente designado: la etnografía tiene la preeminencia y organiza el conjunto, mientras que el discurso artístico ocupa un lugar secundario y enriquece la manera de mirar estas obras.

El 14 de marzo de 1930 fue presentado el tótem ofrecido por la Canadian National Railways, y el 27 de junio fueron inaugurados el vestíbulo de la entrada, donde había sido instalada la cabeza pascuana moai, y la sala de Oceanía que había sido reorganizada provisoriamente. Estos eventos anunciaban la resurrección de Trocadero. Pero fue realmente a partir de junio de 1932, cuando inició la apertura de las salas del museo, e inicialmente aquellas destinadas a las exposiciones temporales, que comenzaron a verse los nuevos principios de museografía etnográfica que regirían la institución. En este sentido, las exposiciones temporales eran ejemplares, puesto que habían sido deliberadamente destinadas a satisfacer las expectativas del gran público. Estas exposiciones de «gran estilo» promovidas por Georges-Henri Rivière - y descritas así en sus propios términos-, pusieron a los visitantes en el camino de vuelta hacia el museo. La exposición «Bronces y marfiles del reino de Benín», organizada por Charles Ratton, Henri Labouret y Georges-Henri Rivière en junio de 1932 fue el brillante «preludio de una serie de manifestaciones destinadas a ilustrar sistemáticamente los diferentes aspectos de la etnología y de las artes primitivas» ${ }^{36}$. De la misma forma en que lo hizo durante la exposición «Artes antiguas de América» de 1928, Georges-Henri Rivière consiguió que el público descubriera una provincia artística y etnológica que era desconocida en Francia. La exposición estaba dividida en dos secciones: una artística, puesta bajo la tutela de Charles Ratton, con 130 piezas; la otra etnológica, preparada por Henri Labouret, en la cual se desplegaba un vasto arsenal etnográfico y documental (fotografías, mapas, reseñas tecnológicas). El éxito era incuestionable: al cabo de un mes, diez mil personas habían visitado una exposición que se había vuelto la sensación del momento, tanto en Francia como en el extranjero. Paul Rivet y Georges-Henri Rivière se habían vuelto protagonistas de la escena cultural parisina, gracias a una cobertura periodística considerable. El dúo aprovechó la ocasión para dar a conocer su programa de renovación, del cual se hizo un gran despliegue publicitario ${ }^{37}$. Al mismo tiempo que se realizaba la exposición sobre Benín, el museo inauguró la sala del Tesoro, "pequeño reino» en donde «ciertas piezas particularmente remarcables desde el punto de vista artístico [...] gozan del privilegio de la extraterritorialidad, con

36 Prólogo anónimo al catálogo de la exposición.

37 Rivet y Rivière, 1 (París, 1931): 3-11. 
un dispositivo y unas clasificaciones más livianos que los científicos, y mejor dispuestas para deleitar nuestros ojos $\rangle^{38}$. Aunque fuese un museo etnográfico, Trocadero no desdeñaba la expresión artística y ante todo buscaba presentar un largo abanico de formas plásticas.

A partir de ese momento, el Museo de Trocadero cambió progresivamente su piel, conjugando un programa de apertura de salas (la de prehistoria exótica en noviembre de 1933, la de Asia en enero de 1934, las de Madagascar y las poblaciones árticas en diciembre de 1934, la de América en marzo de 1935) con un conjunto de exposiciones temporales (una buena cuarentena hasta agosto de 1935, entre las cuales se cuenta la célebre exposición sobre el Sahara en mayo de 1934 que atrajo a más de 70.000 visitantes y la de la misión en la Isla de Pascua, que jugaban con los dos registros, el de lo etnográfico y el de lo artístico). El MET había dejado de ser tildado como una «tienda de barati$1 l o »{ }^{39}$, para pasar a ser comparado con una «inteligente relojería». Los objetos eran limpios, poseían sus reseñas, venían descritos sobre la base de un sólido aparato de informaciones etnográficas, los artefactos indígenas eran tratados como «piezas de convicción» y «testigos» de una civilización dada, dentro de una museografía bastante sobria ${ }^{40}$. Todo esto implicaba un cambio en la naturaleza de la percepción del objeto primitivo que no sabía — ni pretendía - pasar desapercibida. La museografía se ponía al servicio de una voluntad tanto científica como política de reformar las mentalidades, de combatir los prejuicios raciales y étnicos y de mostrar la unidad del ser humano dentro de una pluralidad de culturas.

\section{LAS Misiones CIENTÍfICAS Y MILITANTES DEL MuSEO DEL HOMBRE}

Es necesario precisar que no había una diferencia sustancial entre el Museo de Etnografía de Trocadero y el Museo del Hombre desde el punto de vista de las misiones que les habían sido encomendadas. Había simplemente una dife-

38 Rivière (París, 1932).

39 Rivet y Rivière, 1 (París, 1931): 3.

40 Cf. En el opúsculo Instructions sommaires pour les collecteurs d'objets ethnographiques (Instrucciones sumarias para recolectores de objetos etnográficos), redactado para la misión Dakar-Djibouti, en mayo de 1931, se afirmaba lo siguiente: «Una colección de objetos sistemáticamente recolectados es entonces un rico conjunto de "piezas de convicción", cuya reunión forma archivos más reveladores y más seguros que los archivos escritos» (pp. 6-7); «El objeto no es más que un testigo y debe ser considerado en función de las indicaciones que aporta sobre una civilización determinada, no según su valor estético» (p. 8). 
rencia de medios (materiales y financieros) y de escala que incidía en el alcance y la resonancia de cada proyecto, y en virtud de la cual la organización del espacio podía verse favorecida. La etnología es una de las ciencias sociales que dispone de un museo para traducir sus conocimientos, objetivos, conceptos y misiones. Raramente se había insistido tanto sobre las misiones de servicio y de educación pública que debía asumir un museo, a fortiori un museo etnológico. Aún más que sus papeles de preservación y de conservación, lo que se afirmaba era la preponderancia de su papel social, dado que Paul Rivet concebía al museo como «un factor esencial de educación popular» ${ }^{41}$. Lugar de conservación de una cultura material que abría sobre el universo mental propio de cada sociedad, el museo buscaba que los objetos que exponía probaran la indefectible solidaridad que une a todos los hombres y demostrar las aptitudes técnicas que tienen en común; así, revestido de un enorme valor, cada uno de esos objetos correspondía a un peldaño en el ascenso hacia el progreso. Al objeto se le asignaba un "positivismo excesivo»" ${ }^{42}$; se convertía en la expresión metonímica de la sociedad que lo produjo, una pieza irrefutable que debía ser usada para poner fin al injusto proceso llevado a cabo contra sociedades condenadas, erróneamente, por su primitivismo, su arcaísmo, su incapacidad para dominar el ambiente natural que las rodea, su ignorancia de la escritura, etc. Esta definición no escapa a una visión teleológica de la historia, evolucionista por principio porque el hombre debe tener motivos de esperanza y mirar con confianza hacia el futuro. «Escuela de optimismo», según la expresión de Paul Rivet, la etnología, gracias a su museo, representaba un contrapunto necesario al materialismo dominante en la sociedad:

A esta labor es a la que me he dedicado, con un alcance social cada vez más evidente puesto que, en efecto, no puede negarse que un estudio profundo del hombre y de las sociedades es una de las herramientas intelectuales más seguras de las cuales disponemos para afrontar los peligros de una civilización en la cual lo económico es todopoderoso ${ }^{43}$.

Así mismo, el museo constituía para él un símbolo de la unidad humana en su diversidad, permitiendo al visitante «impregnarse un poco de ese espíritu de relatividad tan necesario en nuestra época de fanatismos» ${ }^{44}$.

Para Paul Rivet y Georges Henri Rivière, un museo etnográfico debía asumir cuatro propósitos, demostrando la implicación cultural, social y política de una etnología preocupada por educar, combatir los prejuicios raciales median-

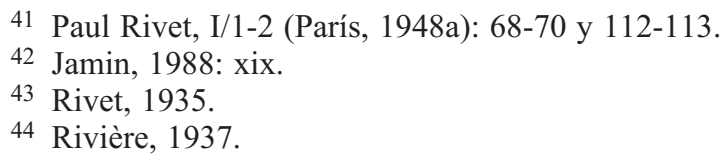


te el conocimiento, ampliar los horizontes de sus conciudadanos y dar su justo valor a las poblaciones coloniales. He aquí los cuatro propósitos:

El primero es un papel científico: las reservas de un museo de etnografía, siempre y cuando estén bien organizadas y dispuestas, son para los estudiosos una mina inagotable de conocimientos, no solo de carácter técnico, sino también sociológico. De hecho, es muy extraño que una costumbre no pueda materializarse de alguna manera a través de uno o varios objetos presentes en un museo etnográfico, y que se conserven con todas las explicaciones necesarias. Este material es indispensable para las escuelas de etnología, de tal forma que los alumnos vayan allí a realizar sus trabajos prácticos.

Su segundo papel es el de educación popular: las galerías abiertas al público exponen los objetos más característicos de las diversas civilizaciones; estos objetos no solo deben ir acompañados de la mayor cantidad de anotaciones, fotografías y mapas, sino que deben distribuirse ejemplares de sus distintas clasificaciones, a fin de presentar todos sus aspectos (clasificaciones topográficas y metódicas). De esta manera, si el público está atento, no solamente recibe lecciones de etnografía propiamente dicha, sino también de geografía, sociología, técnica, etc.

El tercero es un papel artístico: ya sea en las galerías públicas o en las reservas que se abran según la demanda, los artistas y artesanos encontrarán en los objetos de arte primitivo, no solo la idea de una multiplicidad de técnicas desconocidas de nuestra civilización, sino una gran cantidad de formas y decorados que renovarán su inspiración.

Por último, tiene un papel nacional: los museos etnográficos son instrumentos incomparables de propaganda colonial (como los museos de Tervuren y de Anvers) y cultural (ver la gran cantidad de museos creados por la Unión Soviética bajo todos los gobiernos de la antigua Rusia europea y asiática - cristalización y exaltación de las nacionalidades oprimidas - en Praga, Varsovia, Helsingfors, antes de la constitución de los Estados checoslovaco, polaco, finlandés, etc.). Para los actuales y los futuros administradores coloniales es un precioso e indispensable centro de documentación sobre las poblaciones que están llamados a administrar ${ }^{45}$.

Esta definición de las cuatro misiones del museo de etnografía de Trocadero data de 1931, aunque no se diferencia demasiado de la que preconizará el Museo del Hombre en 1938, excepto por tres cosas: el título revolucionario del museo, su carácter innovador y su marcado acento sobre el concepto de

45 Nota del 14 de diciembre de 1931, BCM, París, Estado, carpeta «Outillage National», 2 AM 1 K74b. 
museo-laboratorio. El nombre mismo de «Museo del Hombre» se amoldaba perfectamente a la intención antropológica de Paul Rivet, caracterizada por la interdisciplinariedad del saber. La astucia de este nombre radicaba, precisamente, en que no privilegiaba ninguna disciplina sino que las incluía a todas, afirmando el primado de la unidad en lo biológico y lo social. Dicha unión no implicaba sin embargo una superioridad de los criterios somáticos y raciales. Los principios de división empleados en la museografía del Palacio de Chaillot se inspiraban en una división según regiones culturales y temáticas y no en un orden racial, ajustándose así a una clasificación étnica. Pero la noción de raza no había desaparecido, aún no había sido descalificada: todavía seguía siendo considerada como una categoría científica operativa que decía algo pertinente sobre el hombre en tanto especie biológica. Incluso había una vasta sala reservada a la antropología física en los nuevos locales del museo, y podían verse cráneos en todas sus secciones. Pese a que Paul Rivet, militante por la igualdad de las razas, rechazó la instrumentación ideológica y política de la noción de raza, esta seguía siendo significativa.

El Museo del Hombre también era un «museo para el hombre» ${ }^{46}$, un museo que debía ponerse al alcance del «hombre del común, es decir, de aquél desprovisto de toda cultura, o que tiene una cultura rudimentaria» ${ }^{47}$. «Para elevarlo hacia el conocimiento», prosigue Paul Rivet,

es necesario despertar su curiosidad y de este modo facilitarle el acceso. Por ende, es indispensable presentarle las colecciones del museo sin pedantería, evitando todo vocabulario técnico. De hecho, todo puede explicarse, expresarse, comentarse en un lenguaje sencillo, accesible a todos. No existe labor más difícil que ésta, pero tampoco existe un objetivo más sublime para un conservador de arte que dedicarse a trabajar en favor de las personas más humildes que visiten el lugar que él preside ${ }^{48}$.

Por esta razón, el Museo del Hombre se enorgullecía de abrir sus puertas en horas de la noche, después de la jornada de trabajo de los empleados y de los obreros.

Concebido para la gran masa, el Museo del Hombre era también un museo-laboratorio, que buscaba ofrecer una amplia gama de servicios científicos destinados a los trabajadores intelectuales, como se les llamaba en los años 30 . Siendo al mismo tiempo centro de documentación científica, de enseñanza y de investigación, el museo pretendía ser también el lugar de conservación de la civilización material. En las salas solo se exponía un diez o un veinte por ciento de las colecciones que era cuidadosamente seleccionado. El ochenta o

46 Rivière, 1937.

47 Rivet, I/1-2 (París, 1948a): 68-70 y 112-113.

48 Idem. 
noventa por ciento restante se clasificaba y ordenaba rigurosamente y se guardaba en reservas que no eran más el «Cafarnaúm» de antaño, sino todo lo contrario, «el cerebro del museo ${ }^{49}$, que permitía a los estudiantes e investigadores familiarizarse con objetos lujosos o aquellos más modestos, pero igualmente importantes, de la vida cotidiana, que podían brindar tanta información sobre el contexto social, como este último podía a su vez brindar información sobre los objetos mismos.

Desde este punto de vista, la creación de un departamento de tecnología cuya prolongación museográfica era la nueva sala de Artes y Técnicas, organizada por Anatole Lewitzky, André Schaeffner y André Leroi-Gourhan, constituía una significativa novedad con la que quería demostrarse la unidad del espíritu humano a través de una habilidad manual y artística común que se ajustaba a cada entorno natural. Esta innovación «aparece ante los ojos de los etnólogos contemporáneos como extraordinariamente moderna, pues va más allá de una jerarquía cultural o un simple inventario geográfico, y se interesa por la variación de las constantes $\rangle^{50}$. Paul Rivet consideraba que la sala de arte y de tecnología comparada tenía un gran valor formativo para el visitante, y que por ende desempeñaba un papel pedagógico fundamental. En una época en que la maquinaria y la «taylorización» se imponían en el mundo industrial moderno, esta sala ponía de relieve el valor del trabajo manual y la habilidad del artesano, su inteligencia adaptativa. Para un socialista convencido como Paul Rivet, este era un argumento de peso: el hombre de pueblo, el obrero manual que visitaba el museo y encontraba en su interior muestras de las industrias primitivas podía encontrar en ello la clave para acceder a una apreciación más justa de las sociedades erróneamente consideradas primitivas. Incluso esto le permitiría identificarse a sí mismo y comprender lo que podía tener en común con esos hombres de otros tiempos: la técnica, el saber hacer. «No hay nada más conmovedor que constatar la perfección de los resultados obtenidos, el producto final de herramientas o de armas, cuando se sabe con qué técnicas rudimentarias se fabricaron $»^{51}$. La posibilidad de considerar la larga evolución de la Humanidad y su lenta emancipación, gracias al progreso técnico, debe llevarnos a entonar un «fabuloso himno de fe y de esperanza» ${ }^{52}$ en honor del trabajo de los seres humanos.

\section{Idem.}

50 Declaraciones de Michel Leiris citadas en Annie Dupuis, XXXIX/3-4 (París, 1999): 524.

51 Paul Rivet, Les enseignements de l'ethnographie, sin fecha [entre 1928 y 1935], p. 3, BCM, Fondo del Instituto de Etnología, París, 2 AM 2 C2.

52 Rivet, 7/2 (París, 1954): 84. 
Paul Rivet sugería incluso una idea iconoclasta que lamentablemente no pudo ponerse en práctica dentro del Museo del Hombre. Junto a las salas tradicionales de exposición, consideraba adjuntar «una pequeña exposición permanente de "bellas" falsificaciones». «Dentro de las colecciones públicas y especialmente en las colecciones privadas existen muchos objetos que, dada la perfección de su factura, la competencia de los artesanos que los han fabricado, pueden engañar al amateur e incluso al especialista ${ }^{53}$. Esta sala les permitiría desarrollar una mirada crítica — $\mathrm{O}$ admirativa — sobre tales objetos y ahorrarse «errores e inversiones inútiles». Esto hubiera constituido un preludio estimulante para abrir una discusión sobre la autenticidad de un objeto etnográfico.

Así las cosas, Rivet no podía concebir una etnología que no estuviera comprometida, que no fuera militante, orientada hacia una mejor comprensión entre pueblos y naciones. El museo era el medio de propaganda ideal para difundir estas ideas, puesto que se inscribía dentro de los asuntos de la urbe y podía intervenir en el orden de las representaciones colectivas. Desde los años 1930 trabajaba en pos de restaurar la dignidad de las poblaciones primitivas y coloniales, valorar su patrimonio y lograr en los visitantes un mayor aprecio por ellas. Era además la época del fascismo y del racismo que instrumentalizaban y desvirtuaban el conocimiento científico, para oprimir y estigmatizar ciertas categorías de personas. Como ciencia del hombre, la etnología debía ser portadora de un discurso alternativo coherente que se opusiera radicalmente a esos excesos. Tras el hundimiento de los valores humanistas en Europa durante la segunda guerra mundial, la etnología - según Rivet - debía devolverle al hombre la confianza y la esperanza, debía incitarlo al optimismo y a ver más allá de las dificultades y los conflictos del momento. Tenía una responsabilidad cívica, pues encarnaba un humanismo nuevo que tenía el deber de mostrar a la humanidad desgarrada el camino de la reconciliación. En una palabra, el etnólogo debía re-encantar la realidad. Paul Rivet estaba muy lejos de desempeñar el rol impuesto a los científicos desde una concepción weberiana; él entrelazaba constantemente los géneros político e intelectual, apoyándose en la autoridad que le daba su saber etnológico para implicarse en el debate políti$\mathrm{co}^{54}$. En efecto, para Paul Rivet, el etnólogo no tenía un derecho de reserva sino un deber de injerencia que debía ejercer constantemente. A la manera de los primeros sociólogos, a quienes tanto inquietaba la decadencia de una sociedad en la que el advenimiento de la Revolución industrial transformaba por completo el orden imperante, Paul Rivet quería volver a estrechar los lazos en-

53 Rivet, I/1-2 (París, 1948a). Rivet VII/2 (París, 1954).

54 Jamin, I/3-4 (París, 1989): 290. 
tre los seres humanos a escala planetaria, luego de los dramas de la segunda guerra mundial, de la Shoah y de los cataclismos nucleares de Hiroshima y Nagasaki. Y no existía para él un lugar más apropiado que los museos etnológicos para liderar ese combate en pro de la unidad en la diversidad y del respeto de las diferencias.

Antes de terminar, quisiera abordar la manera en que Rivet entendía los lazos entre el objeto etnográfico y la noción de cultura, así como su aplicación concreta en el marco del Museo del Hombre. Paul Rivet era un hombre de paradojas: era un médico militar de formación que le había dado decididamente la espalda a la antropometría en aras de su pasión por las lenguas y los artefactos, y de su convicción de que el hombre fabricaba su propia cultura, su sociedad, le imprimía su sello y al mismo tiempo era moldeado por esa sociedad. Yo partiría de una paradoja que Michel Leiris subrayó en su momento. Esta paradoja está grabada con letras capitales en el frontispicio del Museo del Hombre, son los versos de Paul Valéry: «Cosas raras o cosas bellas / aquí sabiamente reunidas / obligan al ojo a mirar / como jamás fueron vistas / cosas todas que están en el mundo» ${ }^{55}$.

Estas palabras oportunas invitan a la reflexión. Pero habría que preguntarse si no hubiera sido mejor encontrarlas en la fachada del Museo del Quai Branly, que es en primer lugar un museo de Bellas Artes y en segundo lugar un museo etnográfico. Las palabras de Paul Valéry han sido asociadas equivocadamente a la filosofía del objeto y de la cultura que se manifiesta en las salas del Museo del Hombre. Una segunda paradoja que debe ser subrayada aquí concierne a la inauguración del Museo del Hombre, en junio de 1938, y durante la cual en lugar de escucharse una antología de cantos del mundo entero fue presentada una obra magna de dos miembros de la vanguardia artística parisina, una Cantata compuesta por Darius Milhaud con letra de Robert Desnos. Puede decirse que este gesto hubiera sido más apropiado en un museo de arte moderno occidental que en un museo etnográfico «exótico». El hecho de haber recurrido a Paul Valéry por un lado y a Milhaud y Desnos por el otro ilustra maravillosamente el talento de fino político y la personalidad provocadora de Paul Rivet, así como demuestra la capacidad que tenía para unir al político y al intelectual. Evocando a Paul Valéry, Rivet buscaba y logró obtener el aval de la academia para ganarse el beneplácito de las instituciones - gesto eminentemente político- mientras que con la Cantata pretendía reforzar los lazos con el mundo del arte moderno parisino, ostensiblemente notorios, puesto que Paul Rivet no

55 «Choses rares ou Choses belles / Ici savamment assemblées / Instruisent l'œil à regarder / Comme jamais choses vues / Toutes choses qui sont au monde». 
era insensible al arte. La genialidad del título «Museo del Hombre» pretendía, igualmente, borrar las fronteras, como si afirmara: «Nada de lo que es humano me resulta extranjero»».

Sin embargo, toda la museografía del Museo del Hombre, tanto la concepción del objeto (analizado como un objeto testimonial) como la de la cultura (entendida como cultura material), estaba en las antípodas de esas alianzas circunstanciales. Inspirado en los preceptos recalcados por Marcel Mauss y Paul Rivet en sus clases en el Instituto de Etnología, Michel Leiris, autor de Instrucciones sumarias para coleccionistas de objetos etnográficos, prevenía a estos mismos coleccionistas contra «las cosas raras o hermosas», contra los prejuicios de la pureza del estilo y de la rareza, retomando la fórmula provocadora de Marcel Mauss sobre el enorme valor informativo y documental de la lata de conservas, comparada con la «joya más suntuosa o el sello más extraño». Al exponer los artefactos en un museo, se expone también a su creador puesto que revela su racionalidad, su concepción del mundo y también, inevitablemente, la parte de imaginación que interviene en esa racionalidad. Para Rivet, quien concebía al Museo del Hombre como el guardián de la cultura material de las sociedades no occidentales, exponer esos objetos, esos artefactos, significaba estudiar y tratar de comprender cómo la cultura se vuelve obra, se fabrica, cómo el hombre transforma el mundo y, al hacerlo, cómo se transforma a sí mismo. Él tenía una visión compleja de esas sociedades, poseedoras de una larga historia, fragmentada, hecha de intercambios, considerándolas sociedades abiertas al mundo. En el Museo del Hombre, Paul Rivet y Georges Henri Rivière desarrollaban una concepción ambientalista del objeto, concreción del estado de desarrollo de una cultura en un momento determinado. Ambos se dedicaban a restituir a esos objetos su valor de uso, pero también lo que podría llamarse su valor agregado; es decir, aquello que el ser humano aporta al trabajarlos, al darle forma a la materia prima en campos tan diversos como la metalurgia, la cerámica, la plumajería, el tejido, etc.

Ya el difusionismo de Rivet transmitía la noción de deuda - en el sentido en el que todas las sociedades se deben algo mutuamente-, noción que adquiere una importancia capital puesto que implica, de facto, una actitud de solidaridad entre todos los hombres que comercian, prestan, intercambian conocimientos, herramientas, objetos, técnicas, instrumentos, plantas, rituales, mitos, etc. Para él, el hombre era antes que nada un homo faber, un ser que fabrica, que se realiza en prácticas indisociablemente manuales e intelectuales. Lejos de preocupaciones exclusivamente estetizantes — puesto que no olvidaba que fabricar un objeto útil podía ser también fabricar un objeto hermoso, siendo él muy sensible a la dimensión estética del objeto-, Rivet ponía en práctica un principio de «caridad epistemológica» que apuntaba a valorar nue- 
vamente las creaciones manuales, los procesos de conocimiento puestos en marcha por el actor creador en el acto de fabricación. En resumen, no dudaba en convocar «los orígenes laboriosos» ${ }^{56}$ de los objetos en exposición. No consideraba esos objetos en exposición como excepcionales por su calidad plástica o de forma, sino, antes que nada y sobre todo por ser objetos de la vida cotidiana, fabricados gracias al ingenio de artesanos desconocidos, de obreros anónimos que contribuyeron a la emancipación del hombre gracias a las herramientas y al saber empírico.

Paul Rivet abogaba por la escritura de otra historia, una historia que no había tenido hasta entonces el honor de ser impresa en los libros, que no se focalizara en los hechos relevantes y en la gestión de los grandes de este mundo, sino que privilegiara, por el contrario, las contribuciones anónimas de los pequeños, de los artesanos de la cotidianidad, de aquellos que mejoraban la calidad de vida sin hacer ruido, sin estruendo, pero de manera duradera y eficaz, poniendo los medios para dominar su ambiente natural, adaptarse a él y explotar sus riquezas. Esta manera de concebir la historia reflejaba una concepción prometeica de la tecnología que lo animaba en su defensa del progreso, el progreso de uno entendido como el progreso de todos, de un patrimonio común. Rivet le daba valor, por su tecnicidad y sus conocimientos del mundo vegetal, a las sociedades que durante tanto tiempo habían sido despreciadas, y le recordaba al hombre blanco, al hombre occidental, la deuda que su sociedad tiene con ellas ${ }^{57}$.

Animado por un ardor pedagógico poco común, consciente de su misión de servicio público, Paul Rivet quería hacer comprender a las masas populares, a los trabajadores manuales que entraran en las salas del museo, todo lo que podían tener en común con las sociedades salvajes y primitivas: el gesto y la palabra, la técnica y el arte. Desplegando argumentaciones y apoyándose en los objetos, intentaba demostrar que se había llevado a cabo un proceso injusto contra esas sociedades condenadas de manera equivocada por su primitivismo, su arcaísmo y su incapacidad para dominar el ambiente natural que las rodeaba. Aunque invocaba la razón para intentar reformar las mentalidades, su aspiración idealista subyacente era también trabajar para darle mayor profundidad a la racionalidad e imaginario occidentales, de manera que pudieran relativizarse las categorías de entendimiento y de aprehensión de la alteridad que le eran propias. Rivet no concebía la etnología de otro modo que como una «escuela de optimismo» ${ }^{58}$ cuyo objeto fundamental era mostrar la unidad del

56 Denis Hollier, 1991: XI.

57 Véase Rivet, 1948b, reproducido en Laurière, 2008: 676.

58 Rivet, I/1 (Bogotá, 1943): 1-6. 
hombre en su diversidad y combatir los prejuicios: raramente un etnólogo se ha implicado de tal manera en una lucha política por promover la concordia humana. Y según Paul Rivet, el Museo del Hombre era la herramienta ideal para alcanzar ese fin.

Al fin de cuentas, el paréntesis encantado duró poco tiempo, no más de una década (1928-1939), durante la cual Paul Rivet asistido primero por Georges-Henri Rivière y después por Anatole Lewitzky y Jacques Soustelle se esforzaron para sacar al museo y a sus objetos del limbo en el que se encontraban, pero al cual regresaron rápidamente, con el crecimiento de la influencia de la antropología estructural, que prestaba mayor atención al mundo de las representaciones sociales y simbólicas que a los artefactos. Si volvemos a pensar sobre la base de conceptos weberianos, aquí podríamos considerar la hipótesis de que, una vez el proyecto del Museo del Hombre fue puesto en marcha, la rutina lo alcanzó rápidamente, y terminó bloqueado por los mecanismos administrativos y las querellas internas entre departamentos científicos (el de prehistoria, el de antropología física y el de etnología). Resulta más que sorprendente constatar la semejanza entre los destinos del Museo del Hombre y del Museo de Artes y Tradiciones Populares ${ }^{59}$, fundados respectivamente por Paul Rivet y Georges-Henri Rivière, ambos desarticulados y despojados de su identidad. Se puede pensar que este sea el régimen normal de existencia y extinción de este tipo de «museos-persona», creación y criatura de su creador, que no logran evitar su desaparición en razón de que sus bases epistemológicas, científicas e incluso ideológicas no tienen la solidez suficiente para resistir los embates del tiempo ni la evolución de la disciplina. Es difícil no estar de acuerdo con Jean Jamin cuando sugiere que «Rivet, hombre de convicciones y de pasiones, pudo equivocarse al definir la etnología menos por su objeto y más por sus objetos, menos por un método y más por una cátedra, menos por un trabajo de campo y más por un lugar, menos por sus conceptos y más por sus orientaciones» ${ }^{60}$.

También hay que decir que el museo padeció enormemente la falta de apoyo de los poderes públicos. El Museo Etnográfico de Trocadero y el Museo del Hombre han debido jugar a fondo sobre la instrumentalización colonial para llamar la atención de los políticos. Es de conocimiento público que el Museo del Hombre vivía únicamente con la recaudación de entradas, por lo cual subsistía humildemente. Frecuentemente se ha dicho que el Museo del Hombre era una creación del Frente Popular. Ciertamente, la fase final de los trabajos

59 Sobre el Museo de ATP, véase Segalen, 2005.

60 Jamin, I/3-4 (París, 1989): 291. 
coincidió con la victoria obtenida por el Frente Popular en mayo de 1936 y esta coyuntura política fue deliberadamente empleada para poner énfasis en la voluntad de educar a las masas, que reflejaba la personalidad de su director. Pero el proyecto provenía de antes, remontaba al año de 1931 y su reestructuración ocurrió en 1933, cuando el gobierno de turno lanzaba el proyecto de la exposición internacional de 1937. Paul Rivet supo recurrir a sus apoyos políticos para obtener los créditos requeridos para terminar los trabajos, entre 1937 y 1938. En cualquier caso, es necesario reconocer que, cualquiera que haya sido el gobierno de turno, siempre ha sido extremadamente difícil convencer a los políticos para desbloquear créditos para un museo de etnología. Ningún gobierno ha considerado este tipo de proyectos como una de sus legítimas prioridades. Siempre ha sido menester que la dirección demostrase una energía increíble para alcanzar sus fines. Georges-Henri Rivière tuvo la misma experiencia con su proyecto del Museo de Artes y Tradiciones Populares, que debió aplazar infinidad de veces. Por este mismo motivo, cuando en 1949 Paul Rivet tomó su jubilación, el Museo del Hombre padeció un rápido decaimiento, habiendo perdido el apoyo de su ministerio de tutela al cual ya no le interesaba su suerte. En esto radica una de las diferencias mayores respecto del $\mathrm{Mu}-$ seo del Quai Branly, que, siendo obra del príncipe, ha gozado de un respaldo constante e importante de la presidencia de la república, lo cual le ha permitido superar muchos obstáculos.

Colonialismo, Primitivismo. LA IMPOSIBLE NEUTRALIDAD AXIOLÓGICA DEL MUSEO ANTROPOLÓGICO

El discurso científico progresista y humanista ha sido desarrollado de manera simultánea a ciertas prácticas de recolección de objetos etnográficos dentro de los países colonizados que resultan ser mucho más reprochables hoy en día desde nuestro punto de vista. El paradigma de la etnografía de salvamento, la urgencia de la recolección de objetos de sociedades en vía de extinción bajo la influencia del contacto con los europeos ha servido como excusa para la realización de prácticas que ahora condenaríamos. No olvidemos que se trataba entonces de mostrar la riqueza de la civilización material de esas sociedades, de valorizar su imagen, y que este objetivo lo justificaba todo. En este sentido, las poblaciones colonizadas fueron doblemente condenadas: tanto por la política colonial como por el enfoque etnográfico, que las condenaron a ser objetos de sumisión política y objetos científicos de museo $^{61}$. Basta con recor-

61 Jamin, 1996: 15. 
dar el orgullo que mostraban Rivet y Rivière cuando admiraban el «botín» obtenido durante la misión Dakar-Djibouti en $1933^{62}$.

Varias veces se ha dicho que la antropología es hija del colonialismo, y no quisiera dar más vueltas en torno a este asunto ya resuelto. Sin embargo, quisiera poner en perspectiva esta afirmación a través del ejemplo del Museo del Hombre. Bien es sabido el fuerte impacto que causaba la situación colonial francesa, en particular en relación con la selección de destinos para la realización de trabajos de campo etnográficos pues los etnógrafos del museo exploraban prioritariamente los países bajo dominación colonial francesa, donde resultaba más fácil acceder sin problemas y trámites a las poblaciones autóctonas. El Museo del Hombre era en su tiempo un museo colonial, lo que se asumía sin complejos, porque era una evidencia para todos, porque era la realidad de la situación geopolítica mundial. Pero, más allá de tal evidencia, ¿cuáles eran las repercusiones científicas inmediatas de esta situación? ¿Acaso las directivas y orientaciones eran dictadas por una suerte de ministerio de las colonias? Si bien es cierto que Mauss y Rivet apelaban a la fibra colonial para legitimar ante los gobernantes de turno la necesidad de financiar la renovación del Museo del Hombre, ¿podemos por ello decir que hubiera repercusiones directas a nivel de las prioridades científicas y profesionales establecidas por Mauss y Rivet? En realidad, las ambiciones de la antropología de los años 1930 (recolectar la cultura material para constituir los archivos de las sociedades primitivas antes de su desaparición, etc.), estaban bastante lejos de las necesidades más concretas, de los problemas que planteaban las poblaciones indígenas para los administradores coloniales, quienes no querían saber nada de sus problemas ni ofrecerles ayuda alguna. Ni Rivet ni Mauss pensaron nunca en elaborar el tipo de conocimiento etnográfico que más le convenía al gobierno colonial, ni las informaciones que podían serle más útiles. Lo que les preocupaba era fortalecer la posición académica de su ciencia, teniendo en cuenta sus propios intereses profesionales. Ambos mostraban tener una concepción instrumental de su relación con la situación colonial de Francia, daban muestras de mucho pragmatismo y realismo ${ }^{63}$.

Volvemos así a tratar de la cuestión política en esta conclusión, aunque lo que perseguíamos era tratar de la relación entre lo bello y lo útil. Esto muestra muy bien que, en la manera de considerar los objetos de los otros - y por lo tanto de considerarse a sí mismo - se revela in fine una visión del mundo y de la humanidad profundamente política e ideológica, algo de lo cual resulta muy

62 Sánchez Durá y López Sanz, 2009.

63 Alice Conklin, 20/2 (Nueva York, 2002): 29-45. 
difícil disociarse. Comúnmente, en la prensa, al museo del Quai Branly suele llamárselo museo de las artes primeras. Si hay una razón para introducir así la variable del tiempo es la de incluir a numerosas sociedades y civilizaciones dentro de los orígenes de la humanidad, dentro de una época mítica en la cual no existiría aún el divorcio entre la naturaleza y la cultura, una época necesariamente perdida, antigua, que simbolizaría una cierta nostalgia.

Pero el paso del tiempo también influye de manera insensible en la transformación del objeto etnográfico. Una vez un objeto es recogido, arrancado de su entorno, ya no le pertenece a quienes lo han materializado, a quienes lo han creado. Al salir de ese lugar, pierde su razón de ser inicial, pierde su valor de uso y, llegado al museo, adquiere un nuevo valor, simbólico. Pasa a estar bajo el control del etnógrafo, quien le otorga una nueva razón de ser, convirtiéndolo en la prueba científica de una cultura material. En 1928, en las salas de Trocadero se mostraban muchas piezas pertenecientes a culturas vivas o contemporáneas que estaban transformándose o en transición, o culturas recientemente extintas, de las cuales aún quedaban sobrevivientes. A través del estudio de su cultura material y de las informaciones provenientes de los trabajos de campo, la etnografía explicaba los fundamentos inmateriales de una cultura.

Ahora, en la mayoría de los casos, los objetos expuestos pertenecían a prácticas sociales extintas: esos objetos habían «envejecido» ${ }^{64}$. Con el tiempo, los objetos etnográficos sufrieron una metamorfosis, dejaron de ser documentos científicos sobre sociedades contemporáneas para convertirse en obras de arte, cargados de historia, conformando un patrimonio. Y el hecho de convertirse en objeto patrimonial implica un cambio de tutela, un deslizamiento de poder en beneficio de la historia del arte, es decir, en detrimento de la etnografía. De hecho, las colecciones ya no crecen a través de objetos recogidos sobre el terreno, sino de objetos comprados en subastas de arte o provenientes de coleccionistas. Preferiblemente se compran objetos antiguos, objetos con pedigrí, que han estado entre las manos de coleccionistas prestigiosos. Estos cambios deben ser relacionados con la evolución de los museos: hoy el museo se define menos por una lógica de investigación, y más por una lógica de exposición y de difusión, lo que implica acudir a las competencias particulares de museógrafos, escenógrafos y conservadores. La etnografía ya no tiene el monopolio — si acaso lo tuvo alguna vez- de la gestión y del discurso sobre esos objetos que son igualmente afectados por el tiempo; y con el paso del tiempo, la naturaleza de estos objetos ha cambiado realmente. En los museos, que en

64 Sobre ese tema, muy importante para entender lo que pasó con el cambio de identidad de los objetos y su incorporación al proyecto del museo del quai Branly, véase Grognet, 2 (París, 2005): 49-63. Grognet, 181 (París, 2007): 173-187. 
su mayoría ya no son etnográficos, sino museos de civilización, lo bello se ha impuesto sobre lo útil, que sigue siendo su camarada, aunque se encuentre rezagado.

\section{REFERENCIAS BIBLIOGRÁFICAS}

Breerette, Geneviève y Edelmann, Frédéric, «Une rencontre avec Georges Henri Rivière. Le musicien muséographe qui inventa aussi les écomusées», Le Monde (París, 8-9 de julio de 1979): 16.

Chiva, Isac, "Georges Henri Rivière: un demi-siècle d'ethnologie de la France», Terrain, 5 (París, 1984): 76-83.

Conklin, Alice, «The new "ethnology" and "La Situation Coloniale in Interwar France"», French Politics, Culture \& Society, 20/2 (Nueva York, 2002): 29-45.

De l'Etoile, Benoît, Le goût des autres. De l'exposition coloniale aux arts premiers, París, Flammarion, 2007.

D’Harcourt, Raoul, «Introduction», Georges Henri Rivière y Alfred Métraux (eds.), Les Arts anciens de l'Amérique, París, Les Editions G. Van Oest, 1928: X-XII.

Dias, Nélia, Le Musée d'ethnographie du Trocadéro (1878-1908). Anthropologie et muséologie en France, París, CNRS, 1991.

Dias, Nélia, «Cultural Difference and Cultural Diversity: the Case of the Musée du Quai Branly», Daniel J. Sherman (ed.), Museums and Difference, Bloomington, Indianapolis, Indiana University Press, 2008: 124-154.

Dupuis, Annie, «A propos de souvenirs inédits de Denise Paulme et Michel Leiris sur la création du Musée de l'Homme en 1936», Cahiers d'études africaines, XXXIX/3-4, 155-156 (París, 1999): 510-537.

Fénéon, Felix, «Iront-ils au Louvre? Enquête sur les arts lointains», Bulletin de la vie artistique, 24, 25, 26 (París, 10 de noviembre, 1 y 15 de diciembre de 1920): 662-669, 693-703, 726-738.

Gorgus, Nina, Le magicien des vitrines, París, Editions de la Maison des Sciences de l'homme, 2003.

Grognet, Fabrice, «Objets de musée, n’avez-vous donc qu'une vie?», Gradhiva, 2 (París, 2005): 49-63.

Grognet, Fabrice, «Musées manquées, objets perdus? L’Autre dans les musées ethnographiques français», L’Homme, 181 (París, 2007): 173-187.

Grognet, Fabrice, Le concept de musée. La patrimonialisation de la culture des "Autres». D’une rive à l'autre, du Trocadéro à Branly: histoire de métamorphoses, doctorado de antropología social, París, EHESS, 2008. 
Guardia, Bruno, «Opinions de MM. François Carnot, Raymond Koechlin, Georges Salles», Les Cahiers de la République des Lettres, des Sciences et des Arts, 39 (París, 1928): 82-83.

Hamy, Ernest-Théodore, Les origines du musée d'ethnographie, París, Jean-Michel Place, 1988.

Hollier, Denis, «La valeur d'usage de l'impossible», Prefacio a la reedición facsímil de la revista de vanguardia Documents, París, Jean-Michel Place, 1991: VII-XXIV.

Jamin, Jean, «Tout était fétiche, Tout devint totem», prefacio a la reedición facsímil del Bulletin du musée d'ethnographie du Trocadéro, París, Jean-Michel Place, 1988: ix-xxii.

Jamin, Jean, «Le savant et le politique: Paul Rivet (1876-1958)», Bulletins et Mémoires de la Société d'Anthropologie, I/3-4 (París, 1989): 277-294.

Jamin, Jean, «Introduction à Miroir de l'Afrique», Michel Leiris, Miroir de l'Afrique, París, Gallimard, Colección Quarto, 1996: 9-59.

Lehmann, Henri, «Section Amérique», Chefs d'œuvre du Musée de l'Homme, París, Caisse nationale des monuments historiques, 1965: 152-190.

Laurière, Christine, «Georges Henri Rivière au Trocadéro. Du magasin de bric-à-brac à la sécheresse de l'étiquette», Gradhiva, 33 (París, 2003): 57-66.

Laurière, Christine, Paul Rivet, le savant et le politique, París, Publications scientifiques du Muséum national d'histoire naturelle, 2008.

Leiris, Michel, «Religion et Folies-Bergère», L’Homme, 96 (París, 1985): 137-140.

Leroux-Dhuys, Jean-François, «Georges Henri Rivière, un homme dans le siècle», $L a$ Muséologie selon Georges Henri Rivière, París, Dunod, 1989: 11-31.

Paudrat, Jean-Louis, «Afrique», William Rubin (ed.), Le Primitivisme dans l'art du 20ème siècle: les artistes modernes devant l'art tribal, París, Flammarion, 1987: 127-175.

Paudrat, Jean-Louis, «Les “arts sauvages" à Paris au seuil des années trente», Art tribal (Arquennes, 1996): 45-57.

Poncetton, François, «Découvrons l'Amérique», Les Cahiers de la République des Lettres, des Sciences et des Arts, 39 (París, 1928): 65.

Price, Sally y Jamin, Jean, «Entretien avec Michel Leiris», Gradhiva, 4 (París, 1988): 29-56.

Price, Sally, Paris Primitive: Jacques Chirac's Museum on the quai Branly, Chicago, University of Chicago Press, 2007.

Rivet, Paul, «Le tricentenaire du Museum national d'histoire naturelle», Marianne (París, 26 de junio de 1935). 
Rivet, Paul, «La Etnología, ciencia del hombre», Revista del Instituto Etnológico nacional, I/1 (Bogotá, 1943): 1-6.

Rivet, Paul, «Organisation d'un musée ethnologique», Museum, I/1-2 (París, 1948a): 68-70 y $112-113$.

Rivet, Paul, «Contribution des civilisations dites inférieures à la civilisation européenne», Les Lettres françaises, 191 (París, 15 de enero de 1948b): 3.

Rivet, Paul, «Musées de l'Homme et compréhension internationale», Museum, 7/2 (París, 1954): 83-86.

Rivet, Paul y Rivière, Georges Henri, «La réorganisation du Musée d'ethnographie du Trocadéro», Bulletin du Musée d'ethnographie du Trocadéro, 1 (París, 1931): 3-11.

Rivière, George Henri, «Le Musée d'ethnographie du Trocadéro», Documents, 1 (París, abril de 1929): 54-58 (en la reedición facsímil de la revista publicada en París, Jean-Michel Place, 1991).

Rivière, Georges Henri, «Musée des beaux-arts ou musée d'ethnographie», Les Cahiers de la République des lettres, des sciences et des arts (París, 1931): 278-282.

Rivière, Georges Henri, "A propos de l'art nègre», Le Figaro artistique illustré (París, agosto-septiembre de 1931): 81-83.

Rivière, Georges Henri, «L'Exposition du Bénin au Musée d'ethnographie du Trocadéro», Les Nouvelles littéraires (París, 9 de julio de 1932).

Rivière, Georges Henri, «En 1937, dans le nouveau Trocadéro s’ouvrira le Musée de l'Homme», Les Nouvelles littéraires, 1937.

Rivière, Georges Henri, «My experience at the Musée d'ethnologie. The Huxley Memorial Lecture 1968», Proceedings of the Royal Anthropological Institute of Great Britain and Ireland, 1968.

Sánchez Durá, Nicolás y Hasan López Sanz (eds.), La misión etnográfica Dakar-Djibouti y el fantasma de África, 1931-1933, Valencia, Universidad de Valencia, 2009.

Segalen, Martine, Vie d'un musée. 1937-2005, París, Stock, 2005.

Ventura, Christelle, La fondation du musée du Quai Branly. Matériaux pour une anthropologie politique et culturelle d'une institution, doctorado de antropología, EHESS, París, 2006.

Williams, Elizabeth, «Art and artifact at the Trocadéro. Ars americana and the primitivist revolution», George W. Jr. Stocking (ed.), Objects and Others. Essays on Museum and Material culture, Madison, University of Wisconsin Press, 1985: 146-166. 
Fecha de recepción: 13 de septiembre de 2011.

Fecha de aceptación: 13 de diciembre de 2011.

\section{Art and Usefulness, the Aesthete and the Ethnographer: The case of Paris' Ethnographic Museum of Trocadero and Museum of Man (1928-1940)}

The complex relationship between art and ethnography has been a major issue in France since the mid 1990s because of the launchof the Quai Branly Museum project, which rekindled heated debates about the respective interest and value of the ethnographic gaze compared to the artistic one regarding non-Western objects. This paper gives some historical depth to this topic by examining events in Paris' Ethnographic Museum of Trocadero and the Museum of Man under the direction of Paul Rivet and then Georges Henri Rivière in the 1930s.

Key words: Anthropological Museum; Paris' Museum of Man; Quai Branly Museum; Paul Rivet; Georges Henri Rivière; art and ethnography. 